\author{
seminário \\ paulista do \\ ensino da história \\ do design \\ 2014
}

\title{
Anais do Seminário Paulista de Ensino da História do Design 2014
}

\section{SUMÁRIO}

Apresentação

Memória da organização do SPEHD 2014

Comissão organizadora

Programação do evento

Palestras e Mesas redondas

As disciplinas

Pesquisa com os participantes do evento

Considerações finais 


\section{APRESENTAÇÃO}

Com o objetivo de proporcionar um espaço para se conhecer o estado da arte do ensino da História do Design nos cursos superiores do estado de São Paulo, um grupo de professores de alguns cursos de design paulistano organizou o que foi o primeiro 'Seminário Paulista do Ensino da História do Design' (SPEHD 2014).

Em alguns encontros da AEnD-Br durante a primeira década do presente século, foi discutida a necessidade de se promover eventos de menor porte nos períodos entre as edições do Congresso Brasileiro de Pesquisa e Desenvolvimento em Design (P\&D Design), nos quais áreas especificas pudessem se reunir como forma de estimular ou amadurecer sua produção acadêmica. Tal proposição foi lembrada em debate realizado no Seminário Internacional Design \& História, realizado em Belo Horizonte no dia 6 de dezembro de 2013 e organizado pelo Centro de Estudos, Teoria, Cultura e Pesquisa em Design da Universidade Estadual de Minas Gerais (UEMG). Na volta do encontro na capital mineira, o prof. Auresnede Pires Stephan (Eddy) considerou que era o momento apropriado para acontecer um evento deste tipo e propôs a docentes atuantes em São Paulo a organização de um evento acadêmico de ensino da História do Design.

Deve-se considerar que a História do Design, como área de pesquisa, e em especial a focada no cenário brasileiro, tem se consolidado nas últimas edições do P\&D Design refletindo o aumento da sua produção acadêmica e de publicações com esse tema ao longo dos últimos 15 anos. Da década de 1990 para cá, também se firmou a inserção do ensino da História do Design nos currículos, assim como cresceu nas ementas de disciplinas de graduação e de pósgraduação o conteúdo sobre esse aspecto da História no Brasil, a partir da divulgação das pesquisas com esse tema.

A interrogação sobre que conteúdo programático está sendo ministrado nas disciplinas de Histórias do Design, motivou o grupo docente paulistano a realizar um evento que pudesse demonstrar um panorama sobre este ensino. Afinal, só no estado de São Paulo existem 32 instituições que ofertam bacharelado na área, das quais 18 delas estão localizadas na capital (considerando aqui bacharelados em Design Digital, Design Gráfico e/ou Design de Produto). Isto sem considerar os cursos de graduação tecnológica.

Como o estado de São Paulo possui o maior número de cursos superiores de design no Brasil, optou-se por um evento regional capaz de esboçar um quadro desse ensino no cenário paulista por meio da apresentação não só dos conteúdos ministrados nas disciplinas, mas também da didática e da avaliação empregadas em sala de aula. Como objetivos específicos o evento pretendeu contribuir para o desenvolvimento didático e pedagógico desse ensino por 
meio da troca de informações e do debate de temas a ele relacionados. 0 evento nasceu da preocupação com a complexidade do ensinar História do Design para alunos de uma área projetual e de como demonstrar a importância das reflexões que esta disciplina pode gerar para o seu desenvolvimento intelectual, para o seu processo criativo e para o papel social de sua profissão.

O SPEHD 2014 foi aberto a docentes, pesquisadores e discentes dos cursos de graduação e pós-graduação stricto e lato-sensu de Design do estado de São Paulo e demais interessados das áreas afins como Educação, História, Arquitetura, Engenharias e Artes. As inscrições foram gratuitas, limitadas à capacidade do auditório cedido pelo Centro Universitário Maria Antonia da Universidade de São Paulo (USP), onde ocorreu o evento nos dias 2 e 3 de maio de 2014.

A estrutura do Seminário foi constituída por apresentações de disciplinas, palestras e mesas redondas.

Dezessete professores apresentaram 21 disciplinas, as quais deveriam conter em sua ementa ou em seu conteúdo programático o tema História do Design abordado em âmbito mundial ou em âmbito nacional. Apesar de ser um evento paulista, o Seminário ainda abriu espaço para apresentações de disciplinas de uma docente da Universidade Federal de Pernambuco (UFPE) e de um professor da Universidade Federal do Paraná (UFPR) incluindo assim um contraponto externo. Mesma intenção ao se ter em entre seus palestrantes um professor da Universidad Del Valle, da Colômbia. No inicio do planejamento do evento a Comissão Organização do evento esperava que cerca de 30 professores dos cursos de graduação de Design do estado de São Paulo se inscrevessem para essas apresentações. Porém, mesmo com a inscrição de metade do numero esperado, consideramos que foi possível se ter um panorama significativo do estado da arte do ensino desta disciplina no cenário paulista. Por outro lado, esta situação permitiu que espaços para perguntas fossem abertos ao final de cada sessão de apresentações. 0 tempo de apresentação de cada disciplina foi de dez minutos. Publicamos nestes Anais do evento artigos sobre as disciplinas apresentadas.

As quatro palestras foram proferidas por cinco professores que abordaram dez disciplinas ministradas em São Paulo e na Colômbia. Duas dessas palestras abordaram iniciativas pioneiras na Faculdade de Arquitetura e Urbanismo (FAU USP) com enfoque na história das técnicas e as outras duas apresentaram sequências de disciplinas de História do Design. As duas mesas redondas, ocorridas ao final de cada dia do Seminário, debateram a relação entre o exercício da docência em História do Design e a formação e experiência profissional do professor responsável pela disciplina.

Além dos 17 docentes que apresentaram trabalhos, inscreveram-se no evento como ouvintes: 35 professores (incluindo um de Minas Gerais, dois do Rio de Janeiro e três do Paraná), 19 estudantes de pós-graduação e profissionais dedicados ao mercado e mais seis 
estudantes de graduação. Do público efetivamente presente no Seminário, cerca de 70 pessoas, um pouco mais da metade eram docentes. A diversidade da audiência demonstrou o interesse corrente pelo tema. Uma breve cobertura do SPEHD 2014, pode ser acessada na internet através do seguinte endereço: http://on.fb.me/1i]mu5f

Como o intuito do Seminário é também estimular outros estados brasileiros a promoverem eventos semelhantes sobre História do Design, apresentamos a seguir uma narrativa da memória da organização do SPEHD ocorrida entre os meses de janeiro e abril de 2014

\section{MEMÓRIA DA ORGANIZAÇÃO DO SPEHD 2014}

A primeira reunião ocorreu no dia 17/01/2014 na sede da pós-graduação da FAU USP localizada na rua Maranhão. Na ocasião formou-se a Comissão Organizadora constituída por professores e alunos de instituições importantes da capital de São Paulo, tendo a frente os professores Eddy da FAAP e Marcos Braga da FAU USP: Ângela Coelho aluna do curso de design da FAU USP, Andréa Almeida professora do curso de design da FAU Mackenzie, Débora Buonano professora do curso de design da Belas Artes, Juan Camilo, aluno doutorando da FAU USP, Patricia Amorim professora do curso de design da ESPM e Patrícia Fonseca professora do curso de design da FAAP.

Nesse momento ficou definido como objetivo geral do seminário, a criação de um espaço para conhecer o estado da arte do ensino da História do Design nos cursos do estado de São Paulo, e como objetivo específico, a contribuição para o desenvolvimento didático e pedagógico desse ensino por meio da troca de informações e do debate de temas relacionados. Duas preocupações eram claras, promover a reflexão sobre a complexidade do ensinar História do Design na atualidade, e a problemática da disciplina frente às mudanças que os cursos de Design vem passando.

O Seminário foi pensado em três partes, apresentação das disciplinas, palestras e mesas redondas. Para apresentação das disciplinas, estabeleceu-se que os professores ministrantes dos cursos de graduação de Design do estado de São Paulo versariam sobre ementa, conteúdo programático, didática das aulas e avaliação. 0 formato dessas apresentações deveria seguir os itens das normas da redação do paper sobre a disciplina, enviado pelo professor no ato da inscrição junto com um arquivo contendo a ementa e o programa oficial da disciplina. Este paper (com até 4000 caracteres sem espaço) além das informações básicas de como a disciplina é dada, localizava-a na grade curricular e traçava considerações sobre a avaliação aplicada e o papel da história do design na formação oferecida pelo curso e a possível percepção dos alunos sobre esse papel. 
No caso das palestras, foi levantado pessoas importantes do contexto do ensino da História do Design e autores de teses e dissertações com abordagem sobre o ensino do design e sua relação com a história. Para as mesas redondas, que tinham o papel de promover a reflexão sobre o que foi apresentado durante o dia do seminário, foi definido o tema do primeiro dia como "A importância da formação em História para ministrar História do Design", e do segundo dia, depoimentos sobre como "Ensinar História do Design e as relações com a formação do docente".

O público alvo traçado: docentes, pesquisadores e discentes dos cursos de graduação e pós-graduação stricto e lato-sensu de Design do estado de São Paulo e demais interessados das áreas afins como educação, história, arquitetura, engenharias e artes.

Foi acertado que os professores da Comissão Organizadora contatariam as suas instituições para apoiar o evento, a ideia é que cada uma fornecesse o coffeebreak de um período do evento. A escolha do Centro Universitário Maria Antonia da USP foi ideal, pela sua localização na região central da capital paulista, por ser instituição pública proporcionando um caráter mais aberto ao evento e a pela tradição em abrigar eventos dessa natureza no cenário cultural paulistano.

Para a criação da programação visual do evento, decidiu-se que um aluno de graduação desenvolveria o projeto e por fim foi escolhida a aluna Yeda Gonçalves da graduação do curso de design do Mackenzie, com a supervisão da professora Andréa.

0 texto das normas de apresentação foi elaborado e o tempo de exposição ficou acertado em 10 minutos para cada exposição de uma disciplina. Definiu-se 42 vagas para apresentação de disciplinas, com prioridade aos docentes paulistas, e 100 vagas no total incluindo palestrantes e ouvintes, com igual prioridade para o público paulista por ser um evento estadual.

Foi feito um levantamento das escolas de design de São Paulo com todos os dados necessários de contatos como coordenador do curso e professores responsáveis pelas disciplinas com História do Design.

Um plano de trabalho foi traçado com reuniões quinzenais até o mês de março e semanais mais próximas do evento, sempre às terças-feiras as $14 \mathrm{~h}$. Definiu-se algumas datas chaves do evento: 11/04 para a inscrição das apresentações de disciplinas, 16/04 para divulgação da aprovação da inscrição e dia/horário das apresentações, 23/04 entrega dos arquivos das apresentação de disciplinas por email e 25/04 para inscrição de ouvintes.

0 esboço da chamada para o evento foi elaborado e colocado em prática no dia 10 de março, após o carnaval. A profa. Patricia Amorim se encarregou de abrir uma página do evento no Facebook e subsidiá-la com informações necessárias. Assim a comunicação sobre o evento 
foi centrada em emails e em uma rede social da internet. A divulgação seria também realizada por cartazes a serem afixados nas instituições com cursos de design.

A identidade visual a ser desenvolvida deveria ser aplicada nos materiais necessários, página do facebook, chamada das inscrições por email, cartaz, folder com a programação do evento, crachá, banner do local do evento, e certificados.

Uma decisão importante foi que ao final do evento seria passada uma ficha ao público presente, para avaliação do evento, tendo o objetivo de recolher sugestões e perspectivas futuras, com as seguintes questões:

1. formação superior (curso ou cursos que realizou) graduação e pós-graduação

2. como começou a ministrar a disciplina (convidado,concurso, necessidade premente pela falta de professores na área)

3. quantos anos atua nesta disciplina

4. qual ou quais instituições em que ministra(ou) a disciplina

5. qual ou quais referências bibliográficas que formataram sua carreira

No dia 18 de fevereiro, a terceira reunião, fechou-se os horários e datas de cada coffeebreak e instituição responsável, bem como o membro da Comissão Organizadora que o acompanharia.

Para as palestras constatou-se que os estudos em pós-graduação e as informações particularmente sobre a disciplina História do Design ou das Artes nos anos 1960 e nos anos 1970 eram raros. Nesta época em São Paulo predominou o ensino da história das artes e das técnicas. Então decidiu-se convidar professores que foram pioneiros neste ensino no cenário paulistano e complementar as palestras com exposição de sequências de disciplinas de História do Design. Os palestrantes contatados e acertados para o primeiro dia do evento foram Julio Katinsky para a abertura na parte da manhã e Lucio Gomes Machado para o início da tarde. As palestras do segundo dia do evento ficaram definidas, de manhã a sequência de historia do curso de Design da FAU USP, a maior identificada até então, e a tarde o detalhamento de Juan Camilo sobre as disciplinas de História do Design da Universidad Univalle da Colombia.

Para as mesas redondas foi decidido que teriam três participantes com 15 minutos para cada um, seguidas de debate. Foi atribuída para a primeira mesa o tema "Ensinar História do Design e as relações com a formação do docente", com depoimentos de Ana Lupinacci, Ethel Leon e Giselle Beluzzo, professoras com formação em graduação fora da área do design. Para a segunda mesa com o tema "A importância da formação em História para ministrar História do Design", com os depoimentos de Marcos Braga, Ana Calvo e Patrícia Amorim. 
Nessa reunião foi aprovada a identidade do evento e estipulado prazo para a apresentação da aplicação em todos os materiais do evento. 0 conceito da identidade reuniu a imagem do estado de São Paulo em uma configuração tipográfica, parâmetros sugeridos pela Comissão. A gráfica da FAU USP cuidou da impressão do cartaz, folder e certificados. 0 email foi habilitado e administrado pelos professores Marcos Braga e Patrícia Amorim.

Foram definidos os membros da Comissão que ficaram responsáveis pela secretaria e traçaram uma lista de todas as tarefas para os dias do evento com o intuito de prever necessidades de monitores e alocações de funções nestes dias. Definiu-se as equipes responsáveis pelo recebimento, checagem e confirmação individual das inscrições. Neste momento foi elaborada a agenda detalhada do evento com todas as datas importantes:

- 25/02 - redesenho da assinatura gráfica do evento para aprovação.

- 05/03 - proposta do flyer para a chamada de inscrições.

- 09/03 - proposta do cartaz.

- 10/03 - soltar a chamada de inscrição

- 11/03 - encaminhar arquivo do cartaz para impressão

- 11/04 - prazo da inscrição para apresentação de disciplinas.

- 12/04 a 14/04 - checagem dos textos dos inscritos para apresentação de disciplinas.

- 15/04 - montagem da programação com horários e nomes de todos os oradores

- 16/04 - prazo para divulgação da aprovação da inscrição, dia e horário das apresentações.

- 17/04 - entrega para gráfica do arquivo para impressão do folder com a programação

- 23/04 - entrega pelos docentes dos arquivos das apresentações de disciplinas por email

- 24/04 a 29/04 - checagem dos arquivos das apresentações de disciplinas

- 25/04 - prazo para inscrição de ouvintes.

- 26/04 a 28/04 - checagem, seleção e confirmação dos 50 primeiros inscritos como ouvintes

- 29/04 e 30/04 - montar crachás, certificados, lista de presença e enquete

Na quarta reunião do dia 11 de março foi apresentado os orçamentos de coffeebreak e foram feitas as últimas correções no cartaz e encaminhado a impressão na FAU USP. Os monitores foram definidos que seriam da ESPM e da FAU USP.

Decidiu-se acrescentar uma mesa de encerramento do evento no dia 03/05 após a mesa redonda. E os horários da programação diária foram traçados na forma como ocorreu o evento. 
Uma nova visita ao espaço do Maria Antonia foi feita no dia 18/04 para avaliar capacidade do auditório, circulação e área do coffebreak, abertura da cozinha as 7h30 e a possibilidade de registro do evento e uso posterior desse registro. 0 registro do evento possibilita enriquecer os Anais e auxilia a divulgação dos resultados do Seminário em outros eventos de design. Nesta visita, recebemos a informação de que os técnicos da instituição estariam em recesso por conta do feriado do dia 01 de maio. Por isso, acionou-se a segunda opção que era um monitor assumir esta função, Pedro Marconi da FAU USP que aceitou essa incumbência e foi treinado pelo técnico do Maria Antonia para operação da mesa de som.

Como o Centro Maria Antonia também não poderia gravar o evento, e devido as dificuldades em conseguir equipes de gravação das instituições em período de final de semana, a solução foi usar o equipamento de gravação dos próprios membros da Comissão Organizadora. A gravação, no entanto só seria divulgada com a permissão do palestrante, e um modelo de autorização de imagem e som foi adotado.

Foi discutida a possibilidade de montar os Anais do evento a partir dos textos entregues para as apresentações dos trabalhos. A Editora Blucher ofereceu mídia online, e foi o meio escolhido para a divulgação dos Anais.

Nesta reunião, Yeda apresentou as propostas para os certificados e diagramação do folder, foram feitos acertos no texto e diagramação.

A situação da inscrição no dia 25/03, era de mais de 50 inscritos para ouvinte, mas destes cerca de 20 eram docentes de SP. Foi decidido confirmar as inscrições destes docentes e solicitar a sua confirmaçãono evento. A partir deste retorno seria montada a lista de presença dos ouvintes. Decidiu-se que no dia 12 de abril, se o número de inscritos de SP for abaixo do esperado, seriam convidados a apresentar disciplinas os docentes de outros estados inscritos como ouvintes para abrir espaço para contra-pontos com o ensino de São Paulo.

Ficou acertado que a partir do dia 08 de abril haveria reunião geral da comissão organizadora toda terça as $14 \mathrm{~h}$.

Na sexta reunião, que aconteceu no dia 08/04, foram definidas as funções no evento: um professor e monitores na recepção, 2 monitores internos no auditório e 1 na porta para controle de freqüência. Foram definidos os professores que mediariam as sessões técnicas, as palestras e um mediador para cada mesa-redonda.

Como até aquele momento haviam 12 apresentações de disciplina de São Paulo, foi decidido abrir espaço e convidar os 6 professores externos que se inscreveram como ouvintes para apresentar suas disciplinas. Estes poderiam compor uma das sessões técnicas e deveriam apresentar o paper e ementa até o dia 14/04. Aproveitando que as inscrições estavam em menor número do que as vagas oferecidas para apresentação de disciplinas resolveu-se reservar um tempo para perguntas da platéia, o que não seria possível com a permanência das 
42 vagas para apresentações que inicialmente nortearam a estrutura do Seminário. Lembramos que a primeira intenção era realizar um evento que possibilitasse conhecer o estado da arte do ensino por meio do máximo de apresentações de disciplinas.

Nesta mesma reunião foi detalhado como seria a checagem do material inscrito sob responsabilidade dos professores Eddy, Marcos, Débora, Andrea e Ângela; a checagem dos inscritos externos ficou com Patrícia Amorim e Marcos.

A sétima reunião ocorreu no dia 15 de abril, foram definidas as quantidade de crachás/adesivos, tipos de certificados e a assinatura nos impressos. A situação da inscrição era de 17 docentes para apresentar disciplinas, sendo dois externos que aceitaram o convite da organização do evento. Foram calculadas 60 vagas disponíveis no total para ouvintes. Os cálculos de vagas eram condicionados à capacidade do auditório que era de no máximo 90 lugares.

A oitava reunião ocorreu no dia 22/04, foram feitos os últimos acertos e revisões dos materiais gráficos do evento, folder da programação, banner, adesivos e certificados.

A situação da inscrição era de 29 docentes de São Paulo e de 6 ouvintes externos confirmados. A partir desse momento as demais vagas foram preenchidas com as inscrições de estudantes de pós-graduação e de profissionais e por fim de estudantes de graduação. A lista de tarefas da secretaria foi definida com a sequência de todos os itens necessários as atividades dos dois dias do evento, as alocações de funções foi finalizada.

A nona e última reunião ocorreu no dia 29/04, na qual foram verificados os detalhes da organização e os materiais gráficos foram distribuídos entre os professores responsáveis. Uma visita ao local do evento foi realizada no dia 30/04 para teste do equipamento de gravação, som e de computação e projeção, além do planejamento final das atividades nos espaços do $3^{\circ}$ andar do prédio do Maria Antonia.

Após a realização do Seminário, a equipe da Comissão Organizadora voltou a se reunir para um balanço do evento e para planejar a divulgação na web e os Anais, atividades que duraram até agosto de 2014. 


\section{COMISSÃO ORGANIZADORA}

A equipe da Comissão Organizadora foi composta por 9 membros $(7$ profs. e 2 alunos de graduação) e contou com o auxilio de 5 monitores ( 3 alunos da ESPM , 1 da FAU USP e 1 profissional formada na São Judas).

\section{Coordenação Geral e Comitê Científico:}

Auresnede Pires Stephan (FAAP)

Marcos da Costa Braga (FAU USP)

\section{Comissão Organizadora:}

Ângela Midea Coelho (FAU USP)

Andrea de Souza Almeida (FAU Mackenzie)

Debora Buonano (Belas Artes)

Juan Buitrago (FAU USP)

Patricia Amorim (ESPM)

Patrícia Helena Soares Fonseca (FAAP)

Yeda Gonçalves de Oliveira (FAU Mackenzie)

\section{Monitores}

Gustavo Schlindwein Botelho (ESPM)

Mariane Ayrosa (ESPM)

Mona Soki Sung (ESPM)

Michele Gonçalves Luiz

Pedro Marconi Silvério (FAU USP)

O Seminário Paulista do Ensino da História do Design foi promovido institucionalmente pela FAU USP e Centro Universitário Maria Antônia, com o apoio de outras quatro instituições de ensino paulistas: Centro Universitário Belas Artes de São Paulo, Escola Superior de Propaganda e Marketing, Fundação Armando Álvares Penteado, Universidade Presbiteriana Mackenzie. 


\section{FAU USP}

Fundada em 1948, a Faculdade de Arquitetura da USP é uma das maiores referências latinoamericanas para o ensino da arquitetura. Seu curso de arquitetura apresentava disciplinas voltadas para o estudo do desenho industrial e da comunicação visual dos anos 1960 aos anos 1990. 0 curso de bacharelado em Design da instituição abriu em 2006.

\section{CENTRO UNIVERSITÁRIO MARIA ANTÔNIA}

O Centro Universitário Maria Antônia é um órgão da USP. Sua função é promover cursos, eventos, seminários, debates e exposições. O prédio do Maria Antônia era a antiga sede da Faculdade de Filosofia, Ciências e Letras da Universidade de São Paulo.

\section{CENTRO UNIVERSITÁRIO BELAS ARTES DE SÃO PAULO}

Os cursos de design foram autorizados a funcionar a partir de agosto de 1984 com a denominação ainda de Faculdade de Belas Artes de São Paulo. Design de Interiores foi implantado nos anos 1990 e o curso de Design de Moda abriu em 2002. Em 2007 foi instituído o Núcleo de Design, que funciona em prédio à parte e abriga os quatro cursos de design da instituição.

\section{ESPM}

A graduação em Design da ESPM (Escola Superior de Propaganda e Marketing) foi implementada em 2004. 0 curso tem ênfase no design visual (gráfico e digital) e é dirigido pela professora Ana Lúcia Lupinacci desde a sua fundação. A ESPM nasceu em 1951, por meio de um projeto de Rodolfo Lima Martensen, atendendo a um convite de Pietro Maria Bardi, então diretor do Museu de Arte de São Paulo (Masp), com o nome de Escola de Propaganda do Masp.

\section{FAAP}

A Faculdade de Artes Plásticas da Faap é uma das pioneiras na implantação de cursos de design em São Paulo. 0 curso de Desenho Industrial e Comunicação Visual da Faculdade de Artes Plásticas da Faap implantada em 1967, foi reconhecido em 1972. A partir de 2015 vai oferecer Design Gráfico, Design de Produto e Design de Interiores.

\section{UNIVERSIDADE PRESBITERIANA MACKENZIE}

A Universidade Presbiteriana Mackenzie implantou seus cursos de Desenho Industrial e Comunicação Visual em 1971, dentro da Faculdade de Arquitetura e Urbanismo da instituição. 


\section{PROGRAMAÇÃO DO EVENTO}

Folder da programação

\section{PALESTRAS E MESAS-REDONDAS}

Além das apresentações das disciplinas de História do Design e correlatas, palestras e mesasredondas integraram a programação do Seminário, contribuindo para a ampliação de reflexões e debates durante o evento. Nesse sentido, destaca-se o esboço de uma cronologia do ensino da disciplina no estado de São Paulo, a ênfase na diversidade de recortes temáticos, teóricos e metodológicos e o estímulo à discussão sobre a função e importância da História do Design na grade curricular e na formação profissional.

Ministrada pelo professor Julio Katinsky, a palestra inaugural abordou a disciplina História das Técnicas, pertencente ao currículo da FAU USP. Partindo de uma contextualização político-social do final dos anos 1960, período em que assumiu a disciplina, Katinsky detalhou seu interesse em investigar historicamente o quadro amplo do processo técnico e tecnológico no Brasil em associação às pesquisas de campo que desenvolveu com seus alunos.

O professor Lucio Gomes Machado apresentou, em sua palestra, uma breve cronologia dos cursos de arquitetura no Brasil. Em seguida, concentrou-se no ensino da história das técnicas voltado ao segmento gráfico e aos experimentos com impressos na oficina tipográfica da FAU USP, a partir da implementação de uma disciplina pioneira sobre história do projeto visual em meados da década de 1970.

No segundo dia do Seminário, os professores Carlos Faggin e Marcos Braga apresentaram pela manhã a sequência de quatro disciplinas de História do Design da graduação em Design da FAU USP. Foram detalhadas as abordagens temáticas de cada uma delas e como tais disciplinas se articulam com a grade curricular e com o estudo e aprofundamento de tópicos da História do Design internacional e no Brasil.

A palestra final do evento ficou a cargo de Juan Camilo Buitrago. Professor na graduação em Design da Universidad del Valle, na cidade de Cali, na Colômbia, Buitrago descreveu a sequência de três disciplinas de História do Design do curso ao qual é vinculado. 0 relato de sua experiência de ensino desenvolvida no país vizinho possibilitou ao Seminário tangenciar uma perspectiva latino-americana da problemática da docência em História do Design.

As duas mesas-redondas, por sua vez, focaram a relação entre o exercício da prática docente em História do Design e a formação e experiência profissional do responsável pela disciplina. A primeira delas reuniu as professoras Ana Lúcia Luppinacci (ESPM), Ethel Leon (Facamp) e Gisela Belluzzo (Universidade Anhembi Morumbi). A mesa final discutiu a importância da formação em História como recurso para a docência em História do Design, 
com os professores Ana Paula Calvo (Mackenzie), Marcos Braga (FAUUSP) e Patricia Amorim (ESPM). Ecoando as inquietações em torno do binômio história-projeto, as palestras e mesasredondas do SPEHD 2014 acabaram reforçando a conexão com questões levantadas nas apresentações de disciplinas, favorecendo e alimentando debates cuja força não se esgota neste evento.

Para assistir as gravações da abertura, das palestras e mesas-redondas acesse os links abaixo.

\section{ABERTURA:}

\section{Auresnede Pires Stephan (FAAP)}

Graduado em Desenho Industrial pela Fundação Armando Álvares Penteado (1970) e mestrado em Educação, Arte e História da Cultura pela Universidade Presbiteriana Mackenzie (2007). Atualmente é professor da Fundação Armando Álvares Penteado, professor da Faculdade Santa Marcelina, professor da Escola Superior de Propaganda e Marketing.

\section{Marcos Braga (FAU USP)}

Graduado em Desenho Industrial pela Universidade Federal do Rio de Janeiro (1985), mestrado em Artes Visuais pela Universidade Federal do Rio de Janeiro (1998) e doutorado em História pela Universidade Federal Fluminense (2005). Atualmente é professor do Departamento de História da Arquitetura e Estética do Projeto - AUH da FAUUSP. https://www.youtube.com/watch?v=clecZbIvc90

\section{PALESTRAS:}

\section{Julio Katinsky}

Graduado em Arquitetura e Urbanismo pela Universidade de São Paulo (1957) e doutorado em Arquitetura e Urbanismo pela Universidade de São Paulo (1973). Atualmente é professor titular da USP e Membro de corpo editorial da Pós, Revista do Programa de Pós-Graduação em Arquitetura e Urbanismo da FAU. https://www.youtube.com/watch?v=plYjQx6fPS4

\section{Lucio Gomes Machado}

Graduado em Arquitetura pela Universidade Presbiteriana Mackenzie (1969), Mestrado (1881) e Doutorado (1992) em Arquitetura e Urbanismo pela USP. Atualmente é professor doutor do Departamento de História da Arquitetura e Estética do Projeto da Faculdade de Arquitetura e Urbanismo da Universidade de São Paulo. Socio-Diretor de GMAA - Gomes Machado Arquitetos Associados Ltda e Linha d'Água Difusão Cultural Ltda. https://www.youtube.com/watch?v=ibG8L ml9Ic\&feature=youtu.be 


\section{Carlos Faggin}

Livre-docente do Departamento de História da Arquitetura e Estética do Projeto, da Faculdade de Arquitetura e Urbanismo da USP. Doutor e mestre em Estruturas Ambientais Urbanas pela Faculdade de Arquitetura e Urbanismo da USP. Possui cursos de especialização em Problemas Urbanos em Países em Desenvolvimento , Harvard University e Questões Urbanas e Arquitetônicas para Habitação Popular pelo Bouwcentrum for International Education em Rotterdam, Holanda. Coordenador Didático da Seção de Produção de Bases Digitais para Arquitetura e Urbanismo (CESAD)

https://www.youtube.com/watch?v=TZobuI-Efas

\section{Marcos da Costa Braga}

Minicurrículo na seção Abertura

https://www.youtube.com/watch?v=TZobuI-Efas

\section{Juan Camilo Buitrago Trujillo}

Graduado em Desenho Industrial - Fundacion Universidad de Bogota Jorge Tadeo Lozano (2001) e mestrado em Maestría en Sociología - UNIVERSIDAD DEL VALLE (2011). Atualmente é professor da UNIVERSIDAD DEL VALLE. Tem experiência na área de Desenho Industrial, com ênfase em História e Teoria do Desenho, atuando principalmente nos seguintes temas: história e sociologia do design, história do desenho na Colômbia, estudo morfológico, cultura material e precolumbian design.

https://www.youtube.com/watch?v=7n56ZXZxBRw\&feature=youtu.be

\section{MESAS-REDONDAS:}

Mesa-redonda I [2 de maio de 2014]

\section{o ensino da História do Design e as relações com a formação do docente}

Mediador Juan Camilo Buitrago

\section{Ana Lúcia Luppinacci}

Doutora (2012) e Mestre (2000) em Educação pela FE-USP (Faculdade de Educação da Universidade de São Paulo), linha de pesquisa Linguagem e Educação. Graduação em Comunicação Social pela PUCCAMP-Pontifícia Universidade Católica de Campinas (1980), especializações em Design Têxtil e Estamparia/ FASM, Educação Artística/FMT, formação em História da Arte/ Escola do MASP. Professora universitária e diretora acadêmica do 
bacharelado em Design e Comunicação Visual da ESPM- Escola Superior de Propaganda e Marketing de São Paulo, desde 2003.

\section{Ethel Leon}

Graduada em Comunicação Social pela Universidade Federal do Rio de Janeiro (1977). Possui mestrado (2006) e doutorado em História e Fundamentos da Arquitetura e do Urbanismo pela Faculdade de Arquitetura e Urbanismo, FAU/USP (2013). Atualmente é professora da Faculdade de Campinas (Facamp), editora chefe da Agitprop, revista brasileira de design (www.agitprop.com.br) e, desde 2012, curadora da programação da Atec Cultural.

\section{Gisela Belluzzo de Campos}

Graduada em Artes Plásticas pela Fundação Armando Álvares Penteado (1980). Doutora em Comunicação e Semiótica pela Pontifícia Universidade Católica de São Paulo (1998) com formação complementar na École des Hautes Études en Sciences Sociales (EHESS), Paris, França; mestre em Comunicação e Semiótica pela Pontifícia Universidade Católica de São Paulo (1993). É pesquisadora e professora titular do Programa de Pós- Graduação: Doutorado e Mestrado da Universidade Anhembi-Morumbi atuando na linha de pesquisa Design, tecnologia linguagem: interfaces. https://www.youtube.com/watch?v=xpEgo4aX xg\&feature=youtu.be

Mesa-redonda II [3 de maio de 2014]

\section{A importância da formação em História para ministrar História do Design}

Mediador Auresnede Pires Stephan

\section{Ana Paula Calvo}

Graduada em História pela Pontifícia Universidade Católica de São Paulo (1991) e Mestrado em Educação, Arte e História da Cultura pela Universidade Presbiteriana Mackenzie (2002). Atualmente é professora pesquisadora do curso de Design da Universidade Presbiteriana Mackenzie.

\section{Marcos da Costa Braga}

Minicurrículo na seção Abertura

\section{Patricia Amorim}

Graduada em Jornalismo pela Universidade Federal de Pernambuco (UFPE/1997) e em Design Gráfico pelo Instituto Federal de Pernambuco (IFPE/2002); especialista em Design da 
Informação pela UFPE (2005) e mestra em Design pela UFPE (2007). Atualmente é doutoranda em Design pela UFPE e professora de História do Design e Projeto Editorial na ESPM-SP além de colaborar com periódicos e editoras escrevendo sobre design.

https://www.youtube.com/watch?v=q8rZwibaGIg

\section{Mesa de encerramento}

Auresnede Pires Stephan

Marcos da Costa Braga

Minicurrículos na seção Abertura

https://www.youtube.com/watch?v=D6fQOxpIFqE\&feature=youtu.be

\section{As disciplinas}

Alguns dados sobre esses professores e as disciplinas nos possibilitam desenhar um perfil do docente que ensina História do Design e conhecer alguns aspectos que configuram essa disciplina nos cursos.

Dos 17 professores que apresentaram as 21 disciplinas, 15 professores são de cursos de São Paulo. Assim, temos um panorama representativo do estado de São Paulo.

Dez professores são graduados em Design. Quatro em Artes, 1 em História, 1 em Arquitetura e 1 em Jornalismo. 0 que significa que a maioria tem formação projetual. E apenas 1 professor entre esses 17 não concluiu ainda o mestrado. Entretanto, 7 também fizeram doutorado, o que demonstra que em geral o professor de História do Design é um docente que procura se qualificar por meio da formação em pesquisa de pós-graduação. 0 tempo em que ministram aulas de História do Design na carreira profissional é variado.

Quanto as disciplinas, 15 são de 10 instituições particulares e 6 disciplinas são de 5 instituições públicas (entre essas apenas três públicas são do estado de São Paulo, o que nos proporciona um panorama maior do universo das instituições particulares).

A maioria das disciplinas (55\%) foi ministrada no $1^{\text {o }}$ ano da grade curricular. 0 que demonstra que a História do Design é na maior parte das vezes entendida como uma disciplina de formação básica dentro dos cursos. A carga horária é muito variada: de 30h a 110h por semestre. Essa situação está relacionada com a quantidade de disciplinas dedicadas a História do Design em um mesmo curso ${ }^{1}$ ou com o papel que essa história tem na formação em Design

\footnotetext{
${ }^{1}$ Seis disciplinas, das 21 apresentadas, são de seis cursos que possuem história do design em um único semestre. Quatro outras disciplinas fazem parte de sequências de 2 disciplinas de história do design, 3 em sequências de 3 disciplinas e 2 em sequências de 4 disciplinas.
} 
oferecida por cada instituição de ensino. Os cursos com maior quantidade de semestres com disciplinas de História do Design são os de maior tempo de existência e com mais tradição de ensino de sua instituição. Percebeu-se em algumas instituições privadas uma tendência a diminuição da carga horária de História, privilegiando-se a formação prática para o mercado. Mesmo assim, é matéria obrigatória nos cursos desses 17 professores.

O conteúdo programático, portanto é também condicionado pela carga horária disponível e pelo papel atribuído a História do Design em cada curso. A maioria foca ou começa a sua história a partir da Revolução Industrial. Poucas disciplinas abordam apenas o século XX ou o período pré-Revolução Industrial. A história do design internacional é composta principalmente pelos movimentos mais conhecidos e o cenário da maioria é Europa e EUA. Apenas duas das 21 disciplinas mencionaram conteúdo sobre outros países da América Latina. Entre as razões para este contraste estão o próprio desconhecimento por parte dos professores sobre a história latino-americana e o predomínio de publicações no Brasil sobre a História do Design nos países mais industrializados.

Entretanto, a História do Design no Brasil está presente em grande parte dessas disciplinas ou nas disciplinas de outros semestres com as quais formam uma sequência. Este fato pode ser reflexo do crescimento da pesquisa e das publicações em História do Design no Brasil e pelo interesse em conhecer o passado da profissão no próprio país como meio de se buscar referências para uma identidade profissional.

A prova escrita e individual é a avaliação mais usada por quase todos os professores. Em seguida está a apresentação de seminários teóricos pelos alunos (em 55\% das disciplinas). Quase a metade das disciplinas adota o projeto como exercício para avaliação e em cinco dessas disciplinas esse projeto é integrado com outras disciplinas do curso.

0 principal papel atribuído a História do Design na formação oferecida pelos cursos, segundo declaração da grande maioria dos 17 professores, seria o de proporcionar repertório e referências para a prática do projeto. Esse seria o papel que a maioria dos alunos de seus cursos também atribuem a essa matéria. Em segundo lugar seria o de conhecer o passado da profissão (incluindo o passado no cenário internacional). Apenas $40 \%$ desses professores declararam que também conseguem focar esse papel no desenvolvimento do pensamento crítico nos alunos sobre o Design na sociedade e na consciência das implicações sociais, econômicas e culturais do Design.

Os artigos que compõe os Anais são relativos às disciplinas apresentadas no SPEHD 2014. Os 17 professores que apresentaram as 21 disciplinas foram:

Alberto Ireneu Puppi - Graduado em Desenho Industrial pela Universidade Federal do Paraná (1980), Mestre em Comunicação e Semiótica pela Pontifícia Universidade Católica de 
São Paulo (1992), é Professor Adjunto do Departamento de Design da Universidade Federal do Paraná desde 1993.

Ana Paula Calvo - Minicurrículo na seção Mesas-redondas

Andrea de Souza Almeida - Graduada em Desenho Industrial na Sociedade Universitária de Santos (1986). Mestre em Comunicação e Artes na Universidade Presbiteriana Mackenzie (1998). Doutora em Ciências da Comunicação na USP (2005). Atualmente é professora universitária e pesquisadora da Universidade Presbiteriana Mackenzie.

Angélica de Morais - Graduada em ARTES VISUAIS pela Universidade Federal de Minas Gerais - EBA/UFMG(2004). Especialista em DESIGN DE MODA pela Universidade FUMEC (2006). Professora das ETECs do Centro Paula Souza, nos cursos de Moda, Comunicação Visual e Design de Interiores.

Arthur de Toledo Verga - Graduado em Desenho Industrial. Mestre em Educação, Arte e História da Cultura pela Universidade Presbiteriana Mackenzie (2005). Atualmente é professor associado contratado em regime PPP (Professor período parcial) na Mackenzie e é docente no curso de Design na Universidade São Judas na disciplina de Teorias do Design.

Débora Gigli Buonano - Graduada em Educação Artística pela Faculdade Mozarteum de São Paulo. Mestra em Educação, Artes e História da Cultura pela Universidade Presbiteriana Mackenzie, Doutoranda do programa Educação, Arte e História da Cultura pela Universidade Presbiteriana Mackenzie-SP. Atualmente é professora do Centro Universitário Belas Artes de São Paulo, Universidade São Judas Tadeu e do SENAC na pós-graduação.

Ethel Leon - Minicurrículo na seção Mesas-redondas

Gisela Belluzzo de Campos - Minicurrículo na seção Mesas-redondas

Helena Rugai Bastos - Graduada em Design Gráfico pela Faculdade de Belas Artes de São Paulo. Mestre em Educação, Arte e História da Cultura pela Universidade Presbiteriana Mackenzie (2004). Doutora em História e Fundamentos da Arquitetura e Urbanismo pela FAU da USP. Professora do Centro Universitário Senac-SP (cursos Design Gráfico, Publicidade e Propaganda) e do Centro Universitário Fieo (Design Digital).

José Neto de Faria - Graduado em Desenho Industrial Projeto do Produto pela Universidade Estadual Paulista Júlio de Mesquita Filho - Unesp. Mestre em Design pela Universidade Anhembi Morumbi - UAM. Atualmente é professor da Universidade Anhembi Morumbi - UAM.

Maria Helena Marmo - Graduada em Desenho Industrial pela Faculdade de Arquitetura, Comunicação e Artes da Universidade Mackenzie; Licenciatura Plena na área de Desenho Industrial pela Universidade São Judas Tadeu. Especialização em Criação Visual e Multimídia 
(Gráfica, TV, Cinema e Internet) pela Universidade São Judas Tadeu; Mestrado em Arquitetura e Urbanismo pela USP. Atua como professora nas Faculdades Oswaldo Cruz.

Marcos da Costa Braga - Minicurrículo na seção Abertura

Nelson Rodrigues da Silva - Graduado com Licenciatura Plena em Educação Artística com habilitação em Artes Plásticas pelo Centro Universitário Belas Artes de São Paulo (1977). Mestre em Educação, Arte e História da Cultura pela Universidade Presbiteriana Mackenzie (2003). Pós Graduação em História da Arte pela Fundação Armando Alvares Penteado (1999). Atualmente é professor do Centro Universitário Belas Artes de São Paulo.

Patricia Amorim - Minicurrículo na seção Mesas-redondas

Patrícia Helena Soares Fonseca - Graduada em Bacharelado em Comunicação Visual pela Fundação Mineira de Arte Aleijadinho (1986). Doutora em Educação, Arte e História da Cultura pela Universidade Presbiteriana Mackenzie, São Paulo (2014). Mestre em Textiles Design for Fashion - Central Saint Martins School of Art and Design, Londres (1990). Atualmente é professora assistente da Fundação Armando Álvares Penteado e professora do Centro Universitário Belas Artes de São Paulo.

Paula da Cruz Landim - Graduada em Arquitetura e Urbanismo pela FAU - USP (1987), Mestre em Geografia pelo Instituto de Geociências e Ciências Exatas da Universidade Estadual Paulista, UNESP (1994), Doutora em Arquitetura e Urbanismo pela FAU - USP (2001), estágio de pós-doutorado na Universidade de Arte e Design de Helsinque na Finlândia (2006-2007), Livre-docente em Design de Produto pela Faculdade de Arquitetura, Artes e Comunicação da UNESP (2009), professora do Departamento de Design da Faculdade de Arquitetura, Artes e Comunicação - FAAC da UNESP - campus de Bauru desde 1988.

Paula Vivana de Rezende e Valadares - Graduada em Desenho Industrial (1995) e mestre em Design (2007) pela UFPE. Integra o corpo docente da UFPE do curso de Design do Campus do Agreste. É membro colaborador do Laboratório de Tipografia do Agreste.

\section{PESQUISA COM OS PARTICIPANTES DO EVENTO}

Como parte das intenções de se conhecer o estado da arte do ensino da História do Design, foi realizada durante o evento uma pesquisa por meio de um questionário distribuído para as pessoas presentes, com questões como formação, tempo de atuação como docente, avaliação do Seminário e sugestões para outros eventos do gênero.

Responderam a enquete 47 pessoas o que representa $67 \%$ do total de participantes do Seminário. Entre os que participaram dessa pesquisa 34 eram docentes ( 29 ministram disciplinas da área de história do design e/ou das artes e 5 de outras áreas), 5 eram profissionais não docentes e 8 eram estudantes de graduação ou pós-graduação. 
Os 34 professores trabalham em 24 instituições de ensino diferentes, das quais 5 são externas ao estado de São Paulo ( UFPE, UFPR, UERJ, UEMG e UFTPR). As particulares somam 15 instituições e todas são de São Paulo. As públicas paulistas são três universidades estaduais e uma escola técnica estadual.

Dos 29 docentes que ministram disciplinas da área de história do design e/ou das artes, 15 professores (52\%) cursaram graduação na área de design e 4 na área de arquitetura, o que caracteriza um perfil de professores que apresentam uma formação projetual. Os demais em número de 10 são formados em História, Comunicação Social, artes plásticas e licenciaturas em educação artística. Dez professores fizeram pós-graduação lato sensu, dos quais apenas dois em uma área de História, a da Arte. Os demais em fizeram em Administração, Moda, Design Gráfico, Arte e Design entre outros.

Vinte e sete docentes (92\%) se titularam com mestrado em quinze áreas diferentes como Artes Visuais, História Social, Literatura, Antropologia, Geografia entre outros. As áreas de concentração com maior número de mestres deste grupo são: Educação, Arte e História da Cultura da Mackenzie com 7, Design e Arquitetura da FAU USP com 4 e Comunicação e Semiótica da PUC-SP com 3. Fica aqui evidente a contribuição da FAU USP e da Universidade Mackenzie, bem como da PUC-SP através dos seus cursos para a titulação de docentes em São Paulo.

Quanto ao Doutorado, onze concluíram, dos quais quatro se formaram em História e Fundamentos da Arquitetura e Design e Arquitetura pela FAU USP e os demais em áreas variadas como 'Tecnologia e Sociedade', ‘Educação, Arte e História da Cultura' e 'Comunicação e Semiótica'.

Foi observado que a maioria desses professores que ministram disciplinas da área de História do Design e/ou das Artes possui na sua formação também a vivência projetual e da produção seja artesanal ou digital.

Os professores desse grupo são de gerações variadas e dão aula na área de História do Design e/ou Artes há tempos também muito variados, indo de um ano a 26 anos.

Na maior parte das vezes foram convidados para substituir outros colegas por motivos que abrangem mudança de instituição, transferências ou que pelas mais diversas situações esses colegas não tinham condições de ministrar as aulas de História do Design ou da Arte. Um fator importante que compõe este cenário é a falta de professores com conhecimento ou formação específica na área. Outras vezes, o motivo para assumir as aulas de História é pela disciplina, através do seu conteúdo, acabar estabelecendo conexões com as disciplinas de projeto. Um fato comum também ocorre quando o docente que atuava na área de História da Arte passa a ministrar conteúdos pertinentes a área do Design. Podemos concluir que são 
poucos aqueles profissionais que traçam como um objetivo desde o inicio da carreira docente a atuação em ensino da História no campo acadêmico do Design.

No computo geral, a avaliação do Seminário feita por todos os que responderam a enquete foi pontuada como excelente, muito bom e que cumpriu com os objetivos de um evento pioneiro no segmento da História do Design em São Paulo.

As sugestões manifestadas nos questionários sobre a possibilidade de futuros encontros da área foram de ordem diversa e da qual destacamos:

- Necessidade de ter acesso a tudo o que ocorreu no seminário (palestras, mesas redondas, bibliografias, links etc.)

- Estabelecer um espaço de tempo, em futuros encontros, para debates.

- Uma reflexão maior no âmbito do design brasileiro, o aspecto cultural regional do nosso país somado a América Latina.

- Um aprofundamento maior nas metodologias e estratégias educacionais.

- Definir a continuidade do Seminário em periodicidade anual ou bienal.

- Formas de inserção da disciplina de história como ferramenta no desenvolvimento projetual e no processo metodológico do design.

- Inserir um processo dinâmico ou workshops práticos durante o evento para a interação dos participantes.

- Discutir um conteúdo básico para a disciplina História do Design

- Articulação com a pesquisa e a extensão

\section{CONSIDERAÇÕES FINAIS}

O formato de seminário atendeu aos objetivos inicialmente propostos, visto que a intenção era conhecer o estado de um campo de conhecimento em um determinado tempo, com a confluência de agendas pessoais. Acreditamos que a partir de um evento com este perfil é possível elaborar reflexões e vislumbrar futuros encontros com formatos distintos que se dediquem, por exemplo, ao debate mais aprofundado das questões em pauta.

A enquete realizada ao final do Seminário demonstrou que o SPEHD 2014 foi considerado um sucesso pelo público participante e apontou também que a área da História do Design é caracterizada pela situação de isolamento dos professores que se dedicam ao seu ensino.

Nos últimos anos, espaços acadêmicos em encontros de docentes ou em programas de pós-graduação têm buscado conhecer e debater a pesquisa em História do Design, algo de fundamental importância. Entretanto, esses eventos não atendem por completo as necessidades de discussões e de troca de informações sobre o ensino dessa História.

Situação que não é muito diferente da qual se encontram professores de outras disciplinas, com exceção talvez dos docentes da área de 'Projeto'. 0 ensino de disciplinas de 
'Projeto é objeto de um número significativo de trabalhos apresentados em congressos, dissertações e teses.

Eventos como o P\&D Design são fóruns valiosos para a troca de informações. Contudo, eles não propiciam um espaço no qual docentes de uma área específica de ensino aprofundam questões didáticas e pedagógicas particulares na forma como ocorrido no SPEHD.

A participação de professores vindos de outros estados do Brasil evidencia que o interesse neste tipo de evento não é exclusivo de São Paulo. Com o evento, percebemos uma grande carência de reflexão dos conteúdos, da didática e da pedagogia na História do Design.

Sabemos que com o SPEHD 2014 foi iniciado um processo de reflexão sobre as diretrizes da metodologia de ensino em História do Design no âmbito paulista. Entretanto, sugerimos a realização de um mapeamento mais detalhado da disciplina nas graduações de São Paulo, levando em consideração aspectos como a integração da História do Design com outras disciplinas.

Por fim, acreditamos que o SPEHD 2014 apresentou os vários níveis de abordagem dos conteúdos e as formas pelas quais as instituições conduzem a disciplina, possibilitando ainda uma abordagem técnica no que diz respeito aos parâmetros atuais das grades, da organização da disciplina e das diferenças entre as instituições.

Como desdobramentos do Seminário, além da publicação dos Anais na Internet, os dados e resultados do evento foram divulgados por meio de uma apresentação no V Congreso Latinoamericano de Enseñanza del Diseño, em Buenos Aires, na Argentina, em julho de 2014. Seguindo sugestões do debate final do SPEHD, a professora Giselle Safar (UEMG) assumiu o compromisso de realizar, em 2015, outro evento sobre História do Design que poderá abordar o ensino e o adensamento dos temas levantados no SPEHD 2014, bem como a pesquisa científica na área, além do recorte da História do Design no Brasil. Deste modo, o Seminário realizado em São Paulo poderá ser o primeiro de uma série que terá condições de proporcionar encontros periódicos relacionados ao tema, que contribuindo para o amadurecimento do ensino e da pesquisa da História do Design no Brasil. 